Goodman, L.S. \& Gilman, A. (1970) The Pharmacological Basis of Therapeutics. Fourth Edition. The Macmillan Co., London, p. 902.

Hessov, I., Kraman-Andersen, C. \& Madsen, B. (1972) Peripheral arterial insufficiency during ergotamine treatment. Danish Medical Bulletin, 19, 236.

Juergens, J.L. \& PAYNe, W.S. (1972) Obstructive diseases of veins. In: Peripheral Vascular Diseases (Ed. by J. F. Fairbairn, J. L. Juergens and J. A. Spittel). Saunders Co., p. 558.
LEWIS, T. (1935) The manner in which necrosis arises in the fowl's comb under ergot poisoning. Clinical Science, 2, 43.

Meyler, L. \& Herxheimer, A. (1972) Side effects of drugs. Excerpta Medica, Vol. 7, 138.

YATER, W.M. \& CAHILL, J.A. (1936) Bilateral gangrene of feet due to ergotamine tartrate used for pruritus of jaundice, report of a case studied arteriographically and pathologically. Journal of American Medical Association, 106, 1625.

\title{
Malignant mucocele of the appendix in a femoral hernia
}

\author{
I. N. NAYAK* \\ M.S., F.R.C.S. \\ Hillingdon Hospital, Uxbridge, Middlesex
}

\begin{abstract}
Summary
A case of malignant mucocele of the appendix caused by constriction of its base at the neck of a femoral hernial sac is described. No similar case has been found after a careful search of the literature.
\end{abstract}

\section{Case report}

History. A 62-year-old female patient was admitted for an elective operation for a femoral hernia. She had noticed a swelling in the right groin which had gradually increased in size over the previous 5 years. The swelling had never been reducible during this period and had caused her little discomfort. Twelve years previously she had undergone a hysterectomy for large uterine fibroids and she had suffered from recurrent attacks of bronchitis for many years.

Examination. The patient was moderately obese and had an irreducible giant right femoral hernia approximately $15 \times 10 \times 7 \mathrm{~cm}$ in size (Fig. 1). This was not tender and a cough impulse was present.

Operation. The hernia was explored through an oblique inguinal incision. The sac contained omentum, transverse colon and the appendix which was constricted at its base by the neck of the sac, and was distended and cystic (Fig. 2). The caecum was normal and there was no evidence of pseudomyxoma peritonei. After reducing the omentum and the transverse colon into the general peritoneal cavity an appendicectomy was performed, care being taken

\footnotetext{
* Present address: Children's Hospital, Medical Center, Boston, U.S.A.
}

not to spill its contents. The peritoneum was closed and the femoral ring repaired by suturing the inguinal ligament to the pectineal ligament. Post operatively she made an uninterrupted recovery.

Pathology. The appendix measured $9 \times 2.5 \times 2.5$ $\mathrm{cm}$, and was filled with mucus distal to a constriction at its base (Fig. 3). Histology showed papillary hyperplasia of the epithelium and invasion of the submucosa and muscle coat (Fig. 4). These features are those of a malignant mucocele of the appendix.

\section{Discussion}

Incidence. The term 'mucocele of the appendix' was first coined by Fere in 1877 though the condition had earlier been recognized by Rokitansky in 1842 and described by Virchow in 1863 (Andrews, Feller and Crenwelge, 1966). Since then over 600 cases have been reported in the literature (Chan King-Pan, 1965). The incidence varies from $0 \cdot 1-0.3 \%$ of surgically removed specimens, and from 0.003 $1.3 \%$ of surgically removed specimens, and from $0.003-1.5 \%$ of autopsy specimens (Andrews et al., 1966). DeGarengeot in 1731 was the first to describe the appendix as the content of a hernial sac and an operation for appendicitis in a femoral hernia was described by Hevin in 1785 (Watson, 1948). Appendix as the sole content of a femoral hernia was probably first reported by Langton in 1891 (Chatterjee, 1966). Appendicocele along with other viscera occurs in $1-1.5 \%$ of all hernias but a pure appendicular hernia is rare, $0.003 \%$ (Watson, 1948). About 240 cases of appendix alone in a femoral hernia have 


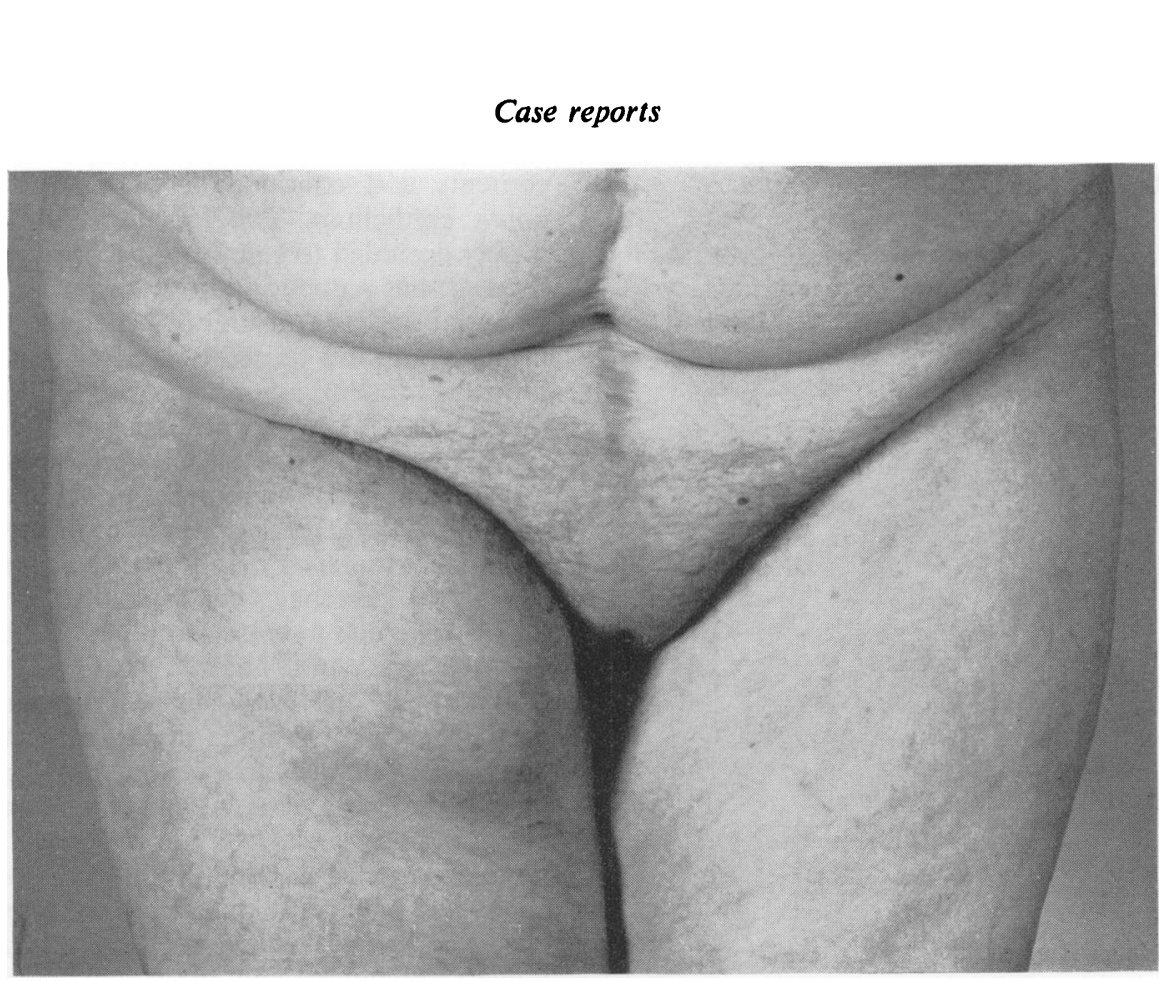

Fig. 1. Giant right femoral hernia.

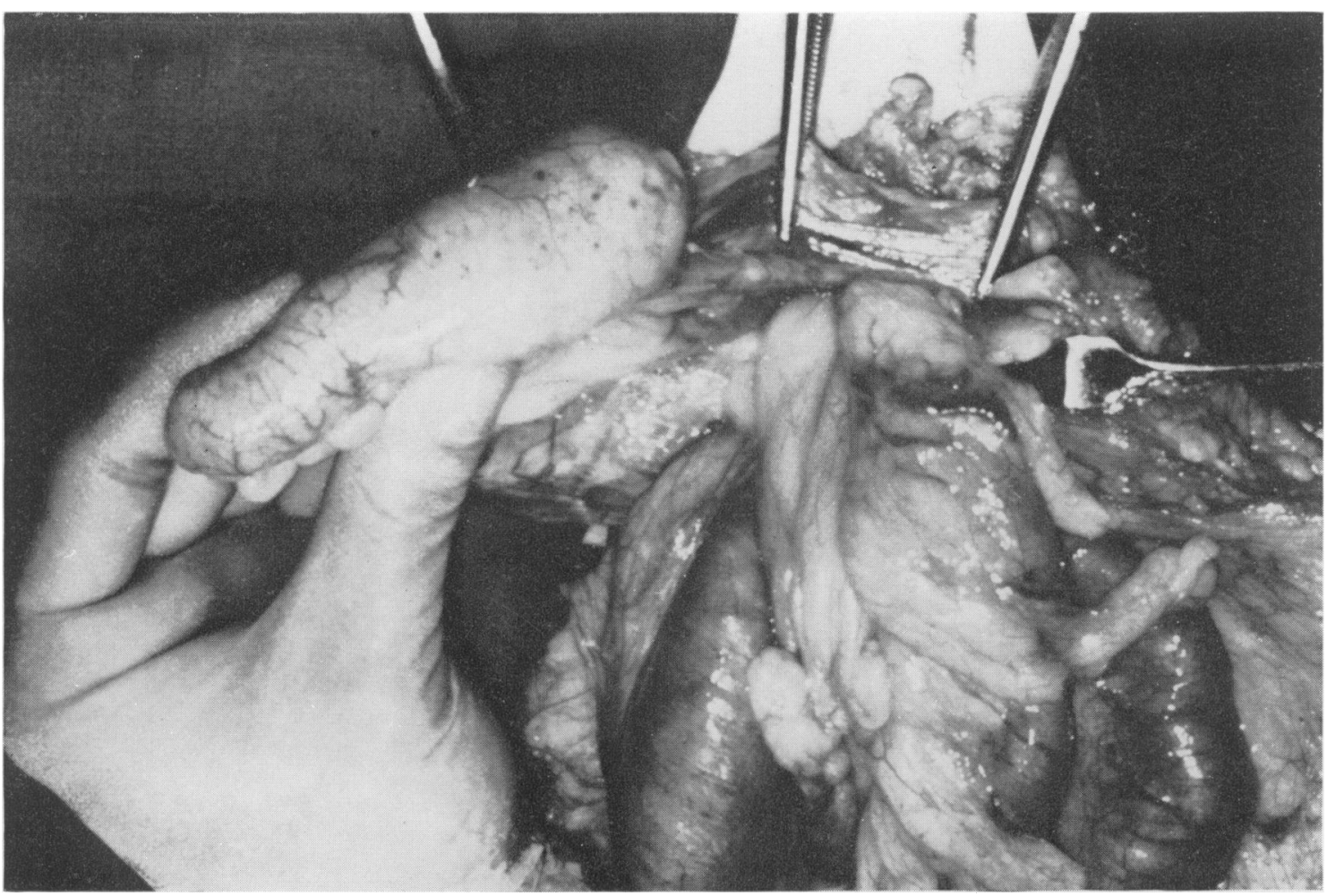

FIG. 2. Operative appearances. 
been reported (Griffin, 1968) and about $98 \%$ of these are in women.

Aetiology. Based on experimental work on rabbits Cheng (1949) postulated three factors necessary for the production of a mucocele of the appendixchronic obstruction of the lumen, sterility of its

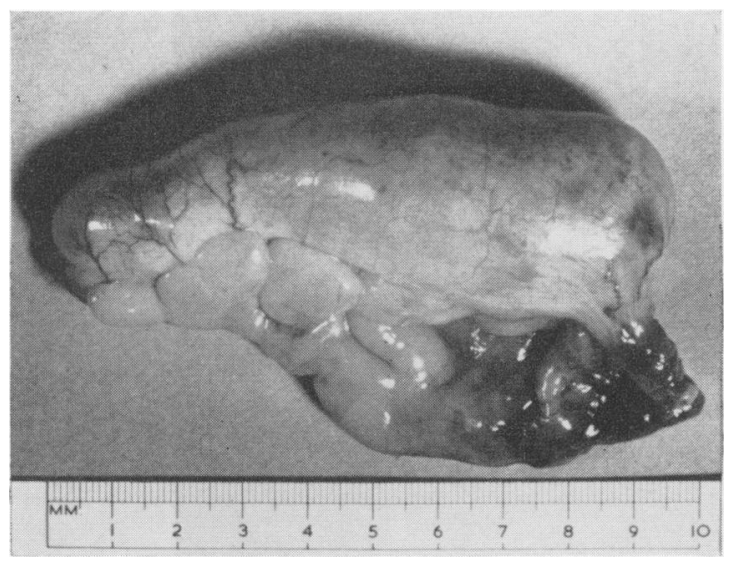

Fig. 3. Mucocele of the appendix. contents and continued secretory activity of the $\frac{2}{\mathscr{Q}}$ lining epithelium. The lumen need not be com- $c$ pletely occluded to cause obstruction. Wilson (1950) showed that reduction of the internal circumference $\stackrel{S}{?}$ to $4 \mathrm{~mm}$ suffices to cause obstruction. The majority $\bar{c}$ of mucoceles are caused by a mural stricture due to previous inflammation (Johnston, 1954). Other $\frac{\text { के }}{7}$ causes are faecal concretions, appendicular and $\stackrel{\varnothing}{\varrho}$ caecal neoplasms, diverticula, multiple polypi (Hilsa- ® beck, Judd and Woolner, 1951); endometriosis (Shemilt, 1949), torsion (Brandes and Peretz, 1965) and caecal mucosal diaphragm (Jenkins and Rack, $\vec{\omega}$ 1967). No case has been described similar to the $\mathscr{S}$ present one due to extra mural constriction.

Pathology. Woodruff and MacDonald (1940) first 3 . distinguished the two types of mucoceles of the appendix, benign and malignant. Majority of $\because$ mucoceles fall into the benign category, they are lined by a single layer of epithelium and they give i rise to only localized non-recurrent variety of $\vec{\sigma}$ pseudomyxoma. A small proportion of mucoceles are of the malignant type, they are lined by hyper- plastic epithelium which has often been called Grade $\frac{D}{O}$ I adenocarcinoma and these may give rise to recurrent generalized pseudomyxoma. Hilsabeck et ab $\vec{\theta}$

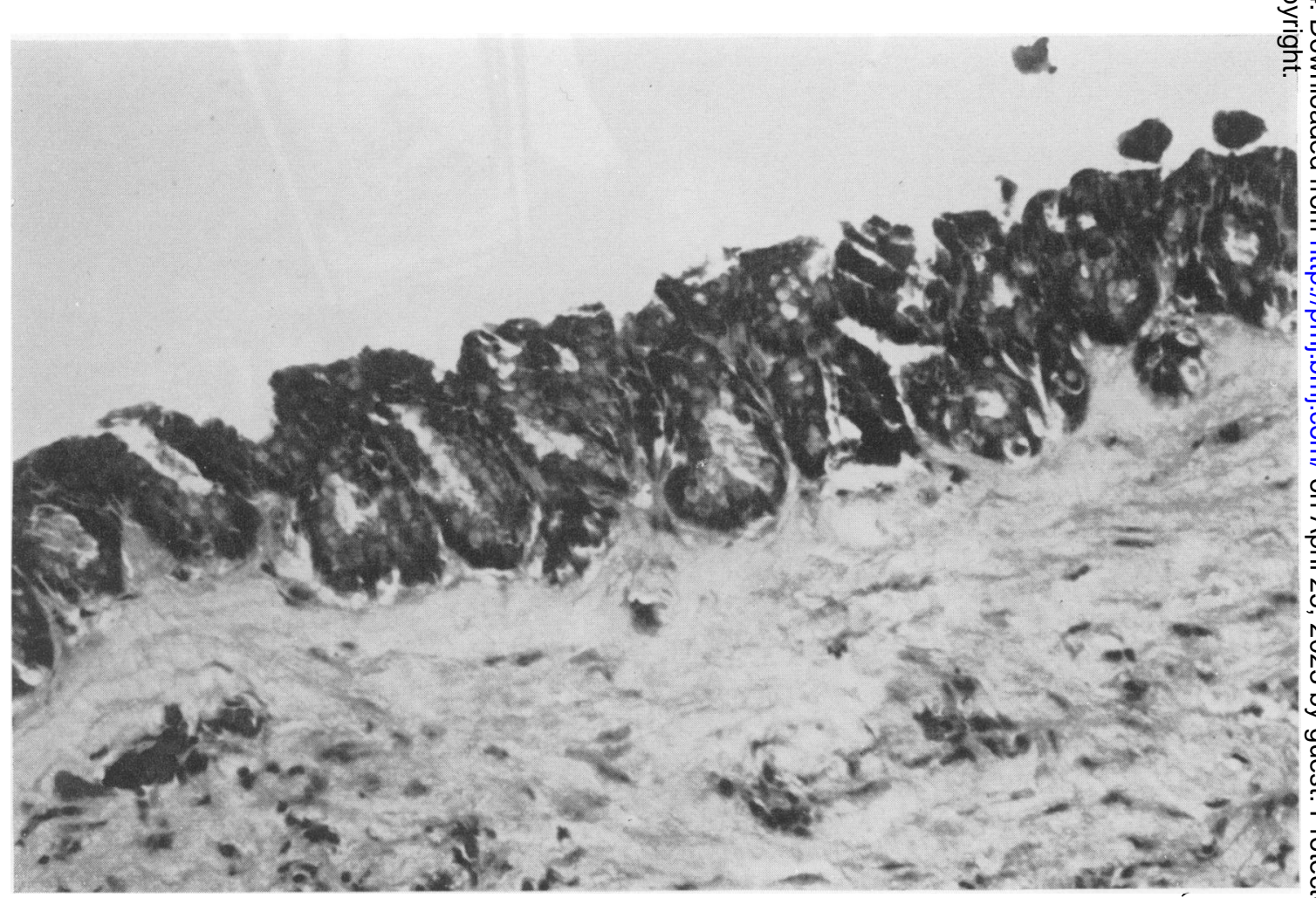

Fig. 4. Papillary hyperplasia of the epithelium and submucosal invasion. H. and E. $(\times 250)$. 
(1951), Woolner (1953) and Broders and Mirand (1971) favour this classification but Carleton (1955) disagrees and has put forward a mechanical concept of the different histological features describing three stages during the formation of all appendicular mucoceles-initial glandular dilatation, subsequent papillary hyperplasia and final epithelial atrophy.

Clinical features. Though the appendix in a femoral hernia is very liable to give rise to such complications as strangulation, retrograde strangulation, appendicitis, appendix abscess and fistulae these are less likely if there are other viscera as well in the hernial sac (Watson, 1948). No case has been reported similar to the present one where an incarcerated appendix has formed a mucocele.

Treatment. Simple appendicectomy without spillage of contents is adequate treatment, even for the malignant variety of mucoceles if the caecum is not involved (Broders et al., 1971).

\section{Acknowledgments}

I should like to thank Mr J. W. P. Bradley, under whose care this patient was treated, for permission to publish details of this case and Mr J. V. Piper for helpful criticism.

\section{References}

Andrews, E.C., Feller, L.W. \& Crenwelge, W.E. (1966) Mucocele of the appendix: a clinical case. Texas Medicine, 62, 61 .

Brandes, J. \& Peretz, A. (1965) Mucocele of the appendix simulating an ovarian tumor. American Journal of Obstetrics and Gynaecology, 92, 579.
Broders, C.W. \& Mirand, R. (1971) Mucocele of the appendix: review of eleven cases and report of two cases. American Surgeon, 37, 434.

Carleton, C.C. (1955) Mucocele of the appendix and peritoneal pseudomyxoma. Archives of Pathology, 60, 39.

Chan King-PaN (1965) Volvulus complicating mucocele of the appendix. British Journal of Surgery, 52, 713.

Chatterjee, S.N. (1966) The appendix in a femoral sac. Journal of the Indian Medical Association, 46, 377.

Cheng, K. (1949) An experimental study of mucocele of the appendix and pseudomyxoma peritonei. Journal of Pathology, 61, 217.

GRIFFIN, J.M. (1968) Incarcerated inflamed appendix in a femoral hernial sac. American Journal of Surgery, 115, 364.

HilsabeCK, J.R., JUDD, E.S. \& WoOlNer, L.B. (1951) Carcinoma of the vermiform appendix. Surgical clinics of North America, 31, 995.

Jenkins, J.D. \& RACK, J.H. (1967) Caecal diaphragm causing mucocele of the appendix and acute appendicitis. British Journal of Surgery, 54, 155.

Johnston, J.H. (1954) Mucocele of the appendix. British Medical Journal, 1, 135.

SHEmiLT, P. (1949) Endometrioma of the caecum causing mucocele of the appendix. British Journal of Surgery, 37, 118.

WATSON, L.F. (1948) Hernia of the vermiform appendix. Hernia, 3rd edn., p. 523. Henry Kimpton: London.

WILSON, R.R. (1950) Diverticula of the appendix and certain factors in their development. British Journal of Surgery, 38, 65.

Woodruff, R. \& Macdonald, J.R. (1940) Benign and malignant cystic tumors of the appendix. Surgery, Gynaecology and Obstetrics, 71, 750.

WOOLNER, L.B. (1953) Carcinoma of the appendix: comments on pathology. Proceedings of the Mayo Clinic, 28, 17. 